\title{
NOVA YORK SELVAGEM: IMAGENS DA CIDADE EM MAGGIE: A GIRL OF THE STREETS, DE STEPHEN CRANE
}

Adriana Carvalho Conde*

RESUMO: Analisamos a participação de Nova York no romance de Stephen Crane, Maggie: a Girl of the Streets, publicado em 1896, que enfatiza a atuação do meio ambiente no destino das pessoas, trazendo à tona a representação daqueles que vivem sob as pressões da miséria em um meio ambiente urbano e hostil. O romance é dotado de uma visão naturalista, em que a personagem Maggie Johnson experimenta a decadência nos bairros dos tenements, em Nova York, em pleno desenvolvimento industrial, no século XIX. Há vários enquadramentos da cidade, os quais ilustram as impressóes do autor sobre sua influência na vida dos e permitem investigar o conte escritores americanos que possuem a visão de wicked cily, acreditando a de dos tenements, provocados pela vida na grande cidade.

PALAVRAS-CHAVE: Stephen Crane; Maggie: a Girl of The streets; Nova York; tenements; romance urbano.
* conde_adriana@hotmail.com

área de Literatura e Vida Social pela

"Júlio de Mesquita Filho", Faculdade

.

ABSTRACT: We have analyzed the participation of New York on the novel by Stephen Crane, Maggie: a Girl of the Streets, published in 1896, which emphasizes the environmental performance in the fate of people, bringing up the representation of those who live under the poverty pressures in a way urban and hostile environment. The novel is endowed with a naturalist view in which the character Maggie Johnson experiences the decay in the neighborhoods of tenements in New York, in the industrial development in the nineteenth century. There are several city frameworks which illustrate the writer's impressions of his influence in the lives of the environment in order to recognize that Crane follows the same model of most Americans writers who have the vision of wicked city, believing in decay of human and moral values in the area of tenements, caused by life in the big city.

KEYWORDS: Stephen Crane; Maggie: a Girl of the Streets; New York; tenements; urban novel. 
1. VAHNENBRUCK. Fiction of New York: the City as a Metaphor in Selected American Texts, p. 17 Todas as traduções presentes neste artigo são de minha responsabilidade.
Em Maggie: a Girl of the Streets (1896), Stephen Crane elege a cidade de Nova York não apenas como cenário da história de Maggie, a jovem descendente de imigrantes irlandeses que se torna prostituta de rua, mas também como um organismo vivo que exerce influência constante sobre o comportamento e as ações de seus habitantes. Segundo Vahnenbruck, assim como outras obras naturalistas, Maggie é um dos romances americanos que realizam uma crítica relevante sobre a influência do meio ambiente proporcionado pela cidade de Nova York no final do século XIX Evidenciando a significativa participação da cidade na obra de Crane, afirma que:

[...] torna-se óbvio quando os leitores notam que a protagonista Maggie não possui muitas ações nem no primeiro nem no último capítulo do romance. Além do mais, o título da primeira versão de 1893, Maggie: a Girl of the Streets (A Story of New York) indica que o autor é, ao menos, mais preocupado com a Cidade que com Maggie. ${ }^{1}$

A personagem protagonista Maggie cresce na Rua Bowery em uma atmosfera confusa e angustiante; ela é apresentada como produto do meio social, pensamento que corresponde perfeitamente às ideias de Herbert Spencer, filósofo britânico, considerado no século XIX o mais importante pensador, comparado a Charles Darwin. Em The Data of Ethics (1879), um trabalho posteriormente incorporado em Os princípios da ética (1892-1893), Spencer observou que "as pessoas se adaptavam aos seus ambientes ao se submeterem à vontade do organismo social ou comunidade à qual pertenciam". ${ }^{2}$

Aparentemente, segundo a crítica, a essência naturalista é caracterizada pelo determinismo, que de acordo com Walcutt "expressa a resignação ou até mesmo o desespero diante do espetáculo da impotência do homem em um universo mecânico". ${ }^{3}$ A maioria dos capítulos tem o início parecido, por meio da descrição do cenário, como uma espécie de congelamento do espaço e preparação dos leitores para o drama que eles contêm. Em tese, Maggie: a Girl of the Streets é muito realista, influenciado pelos expoentes Willian Dean Howells e Hamlin Garlan, acreditando detalhar fielmente a realidade, pois o realismo desejou retratar o homem e a sociedade abstendo-se da idealização romântica, e o naturalismo, expressão do realismo, relacionou o homem comum à sociedade através da denúncia dos problemas sociais, influenciados pelo pensamento darwinista e pela doutrina filosófica do determinismo de Spencer, que toma o indivíduo não como sujeito de sua própria história, mas como alguém que pode ser manipulado por forças morais, econômicas e sociais que estão além de seu controle.

O realismo destaca as cores locais, descrevendo a vida de gente comum, definida pelas lutas sociais, aspecto das nações
2. HAYES. Maggie: a Girl of the Streets: a Story of New York, p. 7

3. WALCUTT. American Literary Naturalism: a Divided Stream, p. 20
EM TESE v. 21 
4. CRANE. Maggie: a Girl of the Streets, p. 39. em modernização. Transita, mais tarde, para o naturalismo, nos Estados Unidos com o expoente Stephen Crane, que demonstra, claramente, que a força do meio ambiente determina o destino de seus personagens. A história aparece cronologicamente em detalhes e é percebida pelo leitor como se este estivesse vendo um álbum de fotografias:

O interior do lugar era coberto de papel de parede oliva e matizes de bronze imitando couro. Um bar de massividade falsificada se estendia ao longo do lado da sala. Atrás, um grande aparador aparentemente de mogno alcançava o teto. Sobre as estantes ficavam pirâmides de vidros cintilantes que nunca foram perturbados. Espelhos colocados em frente ao aparador os multiplicavam. Limões, laranjas e guardanapos de papel, arranjados com precisão matemática, Sentavam entre os vidros [...].

Ao selecionar o romance de Crane, verificamos que as figuras que ilustram a narrativa são caracterizadas como vilões, alcoólatras, prostitutas; como uma massa de pessoas degradadas pelo ambiente. A obra chamou a atenção da crítica ao tocar ironicamente em questões referentes à proliferação dos vícios e da violência na cidade de Nova York. Ao escrever Maggie: a Girl of the Streets, Crane rebela-se contra a representação pitoresca da pobreza, adotada na escrita de importantes romancistas cosmopolitas que frequentemente denunciavam os problemas sociais, como Jack London, Frank Norris,
Henry James, Willian Howells, Edgar Fawcett e até mesmo Theodore Dreiser. Fine esclarece que esses autores possuem uma visão romântica da região dos tenements, expressando uma perspectiva de certo modo sensacionalista da realidade da classe baixa, e pronuncia o seguinte a esse respeito:

A pobreza é raramente degradante; mais frequentemente é enobrecedora. Os homens são trabalhadores honestos e cordatos; as mulheres, abnegadas, corajosas, invioláveis ou cruelmente traídas. Se a heroína cede às investidas de seu sedutor, é apenas após ter travado uma longa e dura luta, como no caso de Cora Strang, a bela flor da "favela" em Edgard Fawcett, The Evil That Men Do (1889). ${ }^{5}$

Stephen Crane oferece em sua narrativa o suporte ideal à crítica, que percebe a evidência da crença no determinismo delineando as ideias do romance. Ambos, estilo e tema podem confirmar o indício. De acordo com Barry R. Schaller, ${ }^{6}$ o romance de Crane reproduz a desilusão do autor em relação ao American Dream, "porque ele tenta mostrar que o ambiente é algo tremendo no mundo e frequentemente molda vidas". Segundo o crítico Eric Solomon, ${ }^{7}$ Maggie seria um ataque em forma de paródia aos romances que mascaravam a realidade vivenciada pela classe pobre. Os textos de Crane possibilitam uma reconstrução retórica da realidade, cuja função é cultural e ideológica.
5. FINE. Abraham Cahan, Stephen Crane and the Romantic Tenement Tale of Nineties, p. 98.

6. SCHALLER. A Vision of American Law: Judging Law, Literature, and the Stories We Tell, p. 104.

7. SOLOMON. Stephen Crane, from Parody to Realism, p. 4. 
8. Slum fiction ou tenement fiction são obras literárias que escolhem como tema a vida da classe baixa, dos moradores dos tenements. A gênese Inglenent fiction tanto na Inglaterra como na America pode ser traçada primeiramente pela propagaça de cortiços ao longo York Chicano Londres, Nova York e Chicago no final do século XIX e pelas advertências sobre

9. GANDAL. Stephen Crane's "Maggie" and the Modern Soul, p. 759.

10. Tenements são habitações também chamadas de tenement houses. Constituemse de apartamentos apertados superpovoados na area pobre da cidade de Nova York. São moradias similares aos cortiços.

11. Manhattan, no final do século XIX, era divida em Lower, Midtown e Uptown.
Crane faz parte do movimento intitulado slum fiction ou tenement fiction, ${ }^{8}$ pois traz à tona o drama da classe operária, retratando os danos das forças econômicas nos que vivem sob as pressões da miséria, em um meio ambiente urbano e hostil, onde são expostas as contradições da vida experimentada nos lugares mais lúgubres de Nova York, trazendo uma protagonista que está longe de ser a nobre heroína doce educada e resignada esperada pelos leitores de romances da época.

O inovador em Stephen Crane reside no fato de representar a classe pobre em sua complexidade e vulnerabilidade, o que implicou quebrar paradigmas e estereótipos difundidos pela literatura romântica, pois revela a exímia crítica feita da situação de uma sociedade fora de controle. A complexidade de Maggie é sentida pela fluência dos diálogos e posicionamentos ideológicos que expressam a visão moral do autor. Keith Gandal declara que: "O romance é um tour de force, uma espécie de contramanifestação. Ele toma um conto familiar, mantém o enredo, mas refaz as caracterizações ou a ação mental, bem como o julgamento moral [...]”. 9

$\mathrm{O}$ romance narra a história de uma jovem pobre e sensível, Maggie Johnson, integrante da classe trabalhadora que vivia em um cortiço - tenement ${ }^{10}$ - experimentando a decadência física e moral, nos bairros do Lower East Side ${ }^{11}$ de Nova York, no século XIX, época em que a cidade apresentava transformações expressivas, com o advento da modernidade, por meio do desenvolvimento industrial e da expansão demográfica, adquirindo já naquela época conformações de uma metrópole. Juntamente com sua família desestruturada, formada por pais alcoólatras e ignorantes, vive na Rua Bowery, ${ }^{12}$ uma área em Manhattan frequentada por boêmios, artistas, escritores e também criminosos, bêbados, prostitutas, vindo a se tornar, nos anos 1800, um lugar da moda. Ansiosa por escapar da vida familiar violenta, apaixona-se e é abandonada por Pete, amigo do irmão, Jimmie, dois valentões de "personalidade beligerante". Quando é desamparada pela família, retorna às ruas e começa a trabalhar como prostituta para sobreviver. Desesperada e vencida pela vida insípida, atira-se nas águas escuras do East River. ${ }^{13}$

É relevante dizer que na primeira edição do romance, em 1893, o autor indica a existência de um homem, no episódio final, que segue Maggie até o rio, fazendo o leitor acreditar que ela possa ter sido assassinada por esse "huge fat man". Porém, na edição de 1896, Crane sugere que Maggie possa ter cometido suicídio, e é nessa publicação que fundamentamos nossas reflexões. Sendo assim, adotamos a posição defendida pelo crítico Pizer, ${ }^{14}$ que insiste no argumento de que Maggie tenha cometido suicídio, confirmando suas afirmações com base em artigos publicados nos anos 1800, nos quais verifica que era muito comum encontrar casos reais de prostitutas que cometiam suicídio se atirando no East River.
12. O nome da Rua Bowery deriva da palavra irlandesa bowerij, que significa "fazenda".
EM TESE
BELO HORIZONTE
v. 21
N. 3
SET.-DEZ. 2015
CONDE. Nova York selvagem: Imagens da cidade em Maggie [...]
P. $164-178$

13. O autor não esclarece o episódio do suicídio, apenas sugere o evento, por meio da utilização de metáforas, o que possibilita pelo menos duas interpretações distintas. O final de Maggie é um assunto controverso na crítica. Alguns críticos apresentam visões opostas. Uns creem que tenha cometido suicídio, e outros que possa ter sido homicídio.

14. PIZER; DOWLING. A Cold Case File Reopened: Was Crane's Maggie Murdered or a Suicide?, p. 36. 
15. SCHÄTZLE. The Reflection of the Metropolis in Stephen Crane's Maggie: a Girl of the Streets, $\mathrm{p}$ 191.

16. CRANE. Maggie: a Girl of the Streets, p. 18.
O tema demonstra que o último refúgio para o indivíduo desesperado é o suicídio, e Schätzle relata que a morte de Maggie, certamente, pode ter sido provocada pela influência da cidade de Nova York, pois a cidade em Maggie: a Girl of the Streets tem um papel não menos importante que o da protagonista e condiz com a mentalidade dos autores naturalistas, que procuravam provar que o ambiente tem força poderosa ao moldar o comportamento das pessoas. ${ }^{15}$

A história trágica de Maggie, irradiada pelo determinismo sórdido, funde elementos de pobreza, ignorância, intolerância, abusos, em um contexto violento e cruel. Em um ambiente imundo e em ruínas, a personagem percorre o caminho, em uma escala descendente, de garota simples, romântica, a prostituta de rua, até cometer suicídio. Crane cria para Maggie um mundo urbano caótico, com ares de pesadelo, que beira à alucinação e à histeria, ao contar a experiência de uma garota que nasce em um lugar descrito como "lamaçal": "A garota Maggie floresceu em uma poça de lama. Ela cresceu para ser a mais rara e maravilhosa produção de um distrito habitacional, uma garota bonita", ${ }^{16}$ descreve o narrador. $\mathrm{O}$ contraste suscitado pela oposição entre os dois termos, remetendo às "flores do mal", expressa a ideia de que é possível nascer uma "flor no lixo". Maggie "Floresceu em um atoleiro", revela o narrador, e parece se tratar de um lugar que a aprisiona, confinando-a ao distrito dos tenements.
A imagem de Maggie, desde os capítulos iniciais, é irônica, porque ela é uma vítima da força destruidora da sociedade. Ela não tem espaço entre a raça humana, pois em tal mundo apenas os fortes sobrevivem. Ela tem de morrer, porque é traída pelas próprias circunstâncias naturais. ${ }^{17}$

A narrativa de Crane evolui para a idealização da realidade de Maggie. Primeiramente ela contempla as novas sensações sugeridas nos encontros com Pete e nos passeios pelas ruas. Começa a vislumbrar a expectativa de uma vida, que, segundo ela, seria maravilhosa, depois passa por um estado de melancolia e cansaço, na busca frustrada da satisfação dos seus desejos, e morre. Maggie é apresentada como uma garota dilacerada pela impossibilidade de realização de seus anseios. São sonhos fadados ao fracasso, prenunciando um final que ponha fim à sua trágica história. No início, Maggie sai com Pete e vai a lugares que a deixam extasiada quanto à quantidade de luzes e à efervescência da Rua Bowery, o que causa nos leitores a impressão de um lugar onde a vida flui freneticamente:

Numa divertida sala havia vinte e oito mesas e vinte e oito mulheres e uma multidão de homens que fumavam. Fazia um forte barulho em u um palco erguido num dos cantos da sala, uma orquestra composta por homens que pareciam terem se encontrado ali por acaso. Garçons ensebados corriam de um lado para o outro, precipitando como abutres sobre os incautos da multidão. ${ }^{18}$
17. A ideia de estar inserida num mundo onde não há como fugir da herança biológica adquirida pela hereditariedade reflete a teoria proposta por Charles Darwin sobre a sobrevivência das espécies. De acordo com ele, apenas as espécies biologicamente resistentes $\mathrm{e}$ fortes podem sobreviver num mundo onde as espécies mais fracas são fadadas a desaparecer.

18. CRANE. Maggie: a Girl of the Streets, p. 50.

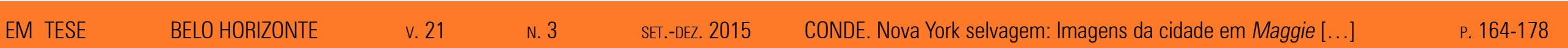


19. SCHALLER. $A$ Vision of American Law: Judging Law, Literature, and the Stories We Tell, p. 104

20. CRANE. Maggie: a Girl of the Streets, p. 29.
O mundo degradante de Maggie é descrito em suas minúcias, e Crane mostra aos leitores os detalhes desagradáveis da existência humana, por meio da representação de um espaço "[...] onde a ideia americana de progresso e bondade não existe" ${ }^{19}$ A linguagem adotada no romance é a linguagem das ruas, dos guetos, de gírias do século XIX carregadas de violência ( go teh hell!, ye damm!). A linguagem torna o romance pesado e triste, o que fez com que muitos editores se recusassem a publicar a história de uma menina esquálida que perambula pelas ruas de Nova York trabalhando como prostituta. Os leitores, críticos e editores acharam que o livro apresentava um tratamento sórdido demais da lower class.

Maggie é considerado um romance urbano em que há vários enquadramentos da cidade de Nova York. Crane parece ser condescendente muito mais culturalmente que moralmente com a visão de "wicked city" dos autores anteriores (Harling, Howells, Dreiser, Fawcett, entre outros), bem como acredita na decadência dos valores humanos e morais da região dos tenements. A cidade aparece como um lugar dominado pelas pessoas e pelas máquinas. "O ar da fábrica de golas e punhos a sufocava", ${ }^{20}$ diz o narrador. A atmosfera densa combina com o espaço também denso, expondo o crescimento urbano, a imigração, refletindo a nova ordem da cidade ditada pela industrialização.
Margolis ${ }^{21}$ aponta essa questão ao observar que: "A visão de uma New York sombria era, certamente, tão real para Crane como era para a maioria dos americanos, mas ele consideraria quaisquer mitos de uma cidade iníqua como condescendência cultural e não como prova de imoralidade", e que:

Em suma, a Nova York de Crane é uma espécie de miniatura metafísica que ele viria a adotar em muitos de seus escritos subsequentes; ou seja, a cidade é uma versão de um universo amoral desprovido de sentido, indiferente à presença do sofrimento da humanidade insignificante. ${ }^{22}$

O mito de que Nova York era o centro da devassidão atingiu proporções enormes, encerrando a ideia de uma "selva de pedras", hostil e ameaçadora. Os escritores naturalistas, Dreiser, Fawcett entre outros, consideravam as grandes cidades, como Chicago e Nova York, um verdadeiro "caldeirão do inferno”. ${ }^{23}$ No imaginário popular do século XIX, a cidade era tida como um símbolo da destruição moral. As mulheres do interior, corrompidas pela vida urbana, eram penalizadas por irem buscar melhoria de vida nas grandes cidades. Joaquim Miller, escritor da tenement fiction norte-americana, refere-se a Nova York como Gottam, em seu livro The Destruction of Gottam (1886), e explica que: "Se Gottam não passar por algum tipo de mudança para melhor, ela pode encontrar a fatalidade do destino da conhecida e glorificada
21. MARGOLIS. New York and Literary Imagination: the City in Twentieth Century Fiction and Drama, p. 99

22. MARGOLIS. New York and Literary Imagination: the City in Twentieth Century Fiction and Drama, p. 99

23. HAPKE. Girls Who Went Wrong: Prostitutes in American Fiction, 1885-1917, p. 15.

$\begin{array}{lllllll}\text { EM TESE } & \text { BELO HORIZONTE } & \text { v. } 21 & \text { N. } 3 & \text { SET.-DEz. } 2015 & \text { CONDE. Nova York selvagem: Imagens da cidade em Maggie }[\ldots] & \text { P. 164-178 }\end{array}$


24. HAPKE. Girls Who Went Wrong: Prostitutes in American Fiction, 1885-1917, p. 15.

25. ALSBURY. As gangs de Nova York: uma história informal do submundo, p. 175 cidade de Babilônia". ${ }^{24}$ Alsbury, ao descrever a cidade de Nova York, mostra em que experiências a ideia de cidade corrompida é baseada:

No encerramento da Guerra Civil [...] Nova York entrou numa era de perversidade sem paralelo [...] Por mais de 25 anos as classes criminosas se regalaram numa orgia de vício e crime, e a metrópole - que na época abrangia apenas a ilha de Manhattan - merecia muito bem o título de "moderna Gomorra" $\left[\ldots . . .^{25}\right.$

O espaço ocupado pela cidade grande no século XIX passa a ser considerado o principal antagonista, e os autores desse período o expressam como sendo responsável pela sina, pela prostituição e pelo fim trágico das personagens. Sendo assim, a cidade torna-se um tema bastante explorado na literatura, pois seria o lugar predileto para inspirar os autores na criação de obras cuja realidade das rua fosse incansavelmente descrita, como na obra de Edgar Fawcett, com a publicação de The Evil That Men Do (1889), em que narra a vida de Cora Strang na cidade de Nova York; Jacob Riis, em How the Other Half Lives (1889), uma coleção de artigos, acompanhados por fotografias das cercanias de Nova York; Edward W. Towsend, com Daughter of Tenements (1895), em que descreve a vida nos bairros italianos; Willian Norr, que pinta o retrato da comunidade chinesa em Stories of Chinatown; Abrahan Cahan, que revela o East Side habitado por judeus em Yekl (1896), entre outros. ${ }^{26}$ Dowling diz que em Crane a cidade é quase uma "entidade física" que impulsiona, aglomera e aprisiona os moradores dos tenements em espaços minúsculos, sem lhes proporcionar nenhum tipo de saída. ${ }^{27}$

Verificamos em cenas frequentemente descritas pelo autor o constante fluxo de pessoas, em que a cidade adquire aspectos imensos no que diz respeito ao crescimento da população de Nova York. As construções e os prédios são antropomorfizados e, à noite, são os bares que seduzem ou mesmo sorriem: "Em uma esquina, um edifício de fachada de vidro lançava um olhar amarelado sobre as calçadas. A boca aberta do salão chamava sedutoramente os que passavam para entrar". ${ }^{28}$ Durante o dia "portas de entradas repulsivas despejavam montes de criancinhas". Existem casas que estão "fechadas como lábios austeros" e outras construções com "severidade de solidez construída sobre suas características”. Dos efeitos dessas imagens emana um tipo de energia que impulsiona os moradores dos cortiços a se manterem confinados em espaços ínfimos. As portas são caracterizadas como "incansáveis", provocando no leitor a ideia de que muita gente entrava e saía do bar. Mais uma vez o autor acentua o grande número de pessoas que compõem o cenário da Nova York onde a boemia é latente:
26. FINE. Abraham Cahan, Stephen Crane and the Romantic Tenement Tale of Nineties, p. 99.

27. DOWLING. Slumming in New York: from the Waterfront to York: from the Waterfront
Mythic Harlem, p. 64.
EM TESE
BELO HORIZONTE
SET.-DEZ. 2015
28. CRANE. Maggie: a Girl of the Streets, p. 39. 
29. CRANE. Maggie: a Girl of the Streets, p. 79.

30. CRANE. Maggie: a Girl of the Streets, p. 56.
As portas incansáveis dos botequins, em constante vaivém, exibiam filas animadas de homens diante de balcões e garçons que corriam de um lado para outro. Uma sala de espetáculos enviava, para a rua, sons enfraquecidos de uma música frenética, maquinal, como se um grupo de músicos fantasmas se estivesse aviando. ${ }^{29}$

Nas impressões da cidade de Nova York do século XIX, Crane expõe os aspectos modernos que a transformavam em plena industrialização. Os elementos que modernizam a cidade são apontados com a presença da eletricidade e do número de pessoas que transitam pelas ruas freneticamente. O leitor pode imaginar as ruas úmidas cheias de gente, a agitação da cidade moderna. A cidade age como personagem da história. O autor insiste em destacar a multidão, o caos da grande cidade e a solidão de seus transeuntes: "Uma mulher desolada percorria a avenida iluminada. A rua estava cheia de pessoas desesperadamente atarefadas. Uma multidão sem fim disparava das escadas das estações mais elevadas e as charretes iam repletas de donos de pacotes". ${ }^{30}$ A cidade com suas regiões escuras aparece ao leitor tão real quanto pode ser dada a conhecer, graças às longas descrições feitas pelo narrador:

Numa noite úmida [...] duas filas intermináveis de carros, puxados por cavalos que deslizavam, chocalhavam em importan- te rua transversal. Uma dúzia de carros de aluguel, de cocheiros envoltos em capas cortava as ruas de um lado para outro. Zumbindo baixinho, lâmpadas elétricas projetavam um brilho fosco [...] Dois ou três teatros derramavam uma multidão nas calçadas varridas pela tempestade [...] Transmudaram-se as calçadas em mares ondulantes de guarda-chuvas. ${ }^{31}$

A decadência de quem reside nos tenements está evidenciada na proliferação desses moradores que se infiltravam nos becos e ruas nas cercanias da Rua Bowery: "As nacionalidades de Bowery iluminavam o palco de todas as direções". ${ }^{32} \mathrm{O}$ autor expõe o aspecto de coletividade enfatizando a numerosa população e lançando mão de recursos narrativos que evidenciam o grande contingente populacional do lugar. As imagens da cidade explodem no romance de Crane e recebem do autor vida própria, como quando ele se refere à chuva que cai nas calçadas tornando-se "mares de guarda-chuvas". Há evidentes construções metafóricas visuais e teatrais. Na descrição meticulosa do distrito dos tenements e da atmosfera da Bowery, Crane revela-se poético, eloquente e entusiasmado, traços percebidos pelo leitor quando o autor acentua a ideia de região lúgubre dos tenements de Nova York, descrita como se segue:

Uma região escura onde, de um edifício ornamentado, dezenas de portas de entrada repulsivas despejavam montes de crian-
31. CRANE. Maggie: a Girl of the Streets, p. 62.

32. CRANE. Maggie: a Girl of the Streets, p. 25.
EM TESE
BELO HORIZONTE
v. 21
N. 3
SET.-DEZ. 2015
CONDE. Nova York selvagem: Imagens da cidade em Maggie [...]
P. $164-178$ 
33. CRANE. Maggie: a Girl of the Streets, p. 6. cinhas na rua e na sarjeta. O vento do princípio do outono levantava a poeira amarela das pedras da rua e arremessava-a nas centenas de janelas. Longas flâmulas de roupas tremulavam nas escadas de emergência. Na rua, crianças brincavam ou brigavam umas com as outras ou permaneciam sentadas, no caminho dos veículos [...] Pessoas apáticas, em curiosa postura de submissão, ou algo assim, sentavam fumando cachimbos nos cantos obscuros. Milhares de odores de comida sendo preparada invadiam a rua. O edifício estremecia e rangia com o peso da humanidade. ${ }^{33}$

O leitor tem a noção de como a população de trabalhadores pobres vivia em Nova York no século XIX. Percebem ser uma rua escura com crianças que brincam e brigam no meio da sujeira, podendo intuitivamente ouvir os rumores barulhentos e sentir os cheiros exalados pelos interiores das moradias, bem como sentir a força dos edifícios que rangiam por causa da aglomeração de pessoas que ali habitavam. Stephen Crane faz uso de adjetivos similares, destacando a atmosfera sombria e ameaçadora, cujos prédios e estrutura são escurecidos pela sujeira das fábricas e pela constante fumaça. Há, por exemplo, "escadas escuras", "corredores frios e sombrios", "paredes manchadas pela poeira escura" "mobília rústica e escassa", que juntos compõem o cenário decadente em que Maggie está inserida com a família. Por causa desse ambiente insalubre Maggie morre no final do romance, demonstrando a força que esse ambiente exerce na vida dela e das pessoas de sua classe.

Não é por acaso que a rua é o palco principal, na obra de Crane. O título do romance deixa evidente o tema. Ela é uma "girl of the streets", refere-se à "dama da noite", indicando que a personagem é a mais baixa forma de prostituta, uma "street walking". O nome "Maggie" é uma gíria em inglês comumente usada para identificar as prostitutas, e a girl of the streets indica que é uma prostituta de rua, tal como qualquer outra garota moradora dos tenements. Irving declara que:

A experiência vivida pela personagem é um exemplo fértil da percepção da rua como o espaço da liberdade, da expressão e da extensão da vida doméstica, o que acarretou ideias polêmicas sobre a mulher que vive dentro das casas e as que transitam pelas ruas. ${ }^{34}$

A ideia de evasão transparece no romance. Tudo se direciona para o lado de fora, para a rua. A vida na Bowery pode ser resumida em brigas, consumo de cerveja, miséria; até mesmo o enredo favorece essa interpretação. A Bowery é descrita como um campo de batalha onde todos travam disputas contra todos. O episódio da briga entre as gangues rivais no capítulo inicial simboliza perfeitamente a atmosfera ofensiva que a rua possui, revelando o tom: "Um garotinho franzino estava em cima de um monte de pedregulhos,
34. IRVING. Gendered Space, Racialized Space: Nativism, the 
35. CRANE. Maggie: a Girl of the Streets, p. 3.

36. CRANE. Maggie: a Girl of the Streets, p. 3. defendendo a honra da Rum Alley, arremessando pedras contra uns moleques da Devil's Row que gritavam e circulavam loucamente o monte, atirando as de volta". ${ }^{35} \mathrm{O}$ ambiente hostil das ruas de Nova York é simbolizado já nesse capítulo inicial, na briga travada entre Jimmie, irmão de Maggie, e os moleques de uma gangue rival. A valentia como meio de sobrevivência é enfatizada nesse episódio, demonstrando a existência de um espaço impregnado de violência e de uma lei que governa a luta pela vida:

Uma pedra havia sido arremessada na boca de Jimmie. Sangue borbulhava sobre seu queixo e ao longo de sua camiseta rasgada. Lágrimas faziam sulcos em suas bochechas machadas de sujeira. Suas pernas magras começaram a tremer e a perder a força, fazendo com que seu pequeno corpo sucumbisse. Suas pragas gritadas na primeira parte da luta haviam mudado para um falatório blasfemo. ${ }^{36}$

Crane se esmera na descrição dessa briga, em que revela a brutalidade e a violência existentes nas ruas. É importante notar que a honra pela qual Jimmie defende, pondo-se em rivalidade com garotos de gangues de rua, equivale aos conceitos de honra e de moral definidos não pela classe média, e sim pela classe baixa. Ao pensarmos que Jimmie vive em um ambiente cuja moral é definida por outros conceitos que não os que definem o termo "honra", como princípios que levam as pessoas a terem condutas virtuosas, percebemos a inversão irônica de Crane, utilizada para acentuar as contradições morais entre duas classes distintas presentes na sociedade de Nova York.

Acreditamos que esteja evidente um dos principais conflitos da época, relacionado ao choque entre os conceitos morais de classes distintas, uma burguesa, conservadora, que ditava a moral da sociedade, e outra pobre, de trabalhadores excluídos dessa sociedade, com princípios morais divergentes da sociedade vitoriana da classe média em Nova York. Maggie tentou fugir, mas teve seus anseios frustrados ao se deparar com a realidade também brutal dos becos e vielas da cidade turbulenta. $O$ romance não parece representar o início de uma cultura na Bowery, mas o final dela, de acordo com Dowling, pois os moradores aceitavam a cultura prevalente da classe média como se os valores morais agissem em julgamentos morais, inconscientes dos códigos de comportamento exteriores à região da Bowery, e acrescenta que:

As personagens de Crane são prostradas pelas contradições psicoculturais que aconteciam. Apesar de Crane mencionar os serviços para a nova cultura de consumo que os habitantes da Bowery aproveitavam, ele não apresenta os teatros, salões de dança, e tavernas como veículos para a dissidência cultural; qualquer dissidência, ao menos na Bowery, teria sido vestígios de um tempo passado. Maggie, em suma, é uma história não de rebelião, mas do conformismo cego à convenção. ${ }^{37}$
37. DOWLING. Slumming in New York: from the Waterfront to mythic Harlem. p. 51.
EM TESE
BELO HORIZONTE
v. 21
N. 3
SET.-DEZ. 2015
CONDE. Nova York selvagem: Imagens da cidade em Maggie [...]
P. $164-178$ 
38. DOWLING. Slumming in New York: from the Waterfront to Mythic Harlem, p. 52.

39. MARGOLIS. New York and Literary Imagination: the City in Twentieth Century Fiction and Drama, p. 93.
Os personagens de Crane simbolizam fragmentos de uma cultura que se rompeu com a industrialização, o comércio, a mentalidade da classe média vitoriana e os efeitos destes sobre a cultura da classe trabalhadora na Bowery. As estratégias narrativas demonstram ideias contraditórias, que revelam as diferenças culturais e morais existentes entre as duas classes sociais distintas. Está claro o significado de lutas de classes, pois certamente Crane aponta que a razão para a falta de crescimento individual de seus personagens está intimamente relacionada aos males existentes na grande cidade. Nesse aspecto, Dowling afirma que:

[...] não há dúvidas de que existia um conflito cultural muito real entre grupos competidores, há uma aura de inevitabilidade como efeito da urbanização na Bowery, esteja isto nas mãos dos Vitorianos ou em alguma outra força cultural de fora [...] reflete a supressão, não a ascendência, daquela cultura singular. ${ }^{38}$

O próprio Stephen Crane declarou certa vez que: “[...] as energias frustradas das subclasses frequentemente as voltam umas contra as outras em vez de contra suas regras. Em outras palavras, os pobres podem não ser sempre violentamente conscientes sobre a classe como alguns cientistas sociais querem nos fazer acreditar". ${ }^{39}$

Em Maggie: a Girl of the Streets, Crane descreve as divergências sociais posicionando os adversários como se estivessem em um ringue, cuja luta é seguida de perto por espectadores curiosos, que torcem para que haja um vencedor no final. Sendo assim, o autor pode demonstrar a desvalorização do caráter e da moral dos moradores dos tenements, acentuando hiperbolicamente os elementos desumanizantes dos personagens que os transformam em guerreiros sanguinários ou mesmo em demônios ávidos por sangue, como na briga de Jimmie com Pete, seu parceiro e quem, aos olhos dele, arruinou a vida de sua irmã Maggie ao seduzi-la: "Os braços dos combatentes rodopiavam no ar feito clavas. Os rostos dos homens, a princípio avermelhados pela cólera, já começavam a adquirir a palidez dos guerreiros mergulhados no sangue e no calor da batalha". ${ }^{40}$

Compreendemos que a violência em Maggie é componente essencial do mundo dos personagens de Crane. Há lutas corporais constantes representativas de ânimos flamejantes. Jimmie, ao perceber ter brigado com a gangue rival sozinho, sem a ajuda dos outros membros, começa, enfurecido, a atacar os outros garotos: "Atiraram-se uns ao outro se engalfinharam e rolaram sobre as pedras". ${ }^{41}$ É importante ressaltar que o autor descreve a cena buscando a expressividade máxima nos adjetivos, como em "faces convulsionadas", que enfatiza a ferocidade das crianças "endemoniadas" ou "verdadeiros assassinos", vista na utilização dos termos cuja forca expressiva faz surgir uma cena espetacular representativa da desordem constante nos bairros da classe trabalhadora:
40. CRANE. Maggie: a Girl of the Streets, p. 43.
EM TESE
BELO HORIZONTE
N. 3
41. CRANE. Maggie: a Girl of the Streets, p. 5. 
42. CRANE. Maggie: a Girl of the Streets, p. 3.

43. SCHALLER. $A$ Vision of American Law: Judging Law, Literature, and Law: Judging Law, Literature,
the Stories We Tell, p. 106.
Urros de ira revigorada emanaram das gargantas da Devil's Row. Moleques esfarrapados à direita golpearam furiosamente o monte de cascalho. Em suas pequenas faces convulsionadas brilhavam os sorrisos de verdadeiros assassinos. Ao se aproximarem, atiravam pedras e estridentemente o amaldiçoavam e saiam correndo. ${ }^{42}$

Ao crescerem nesse ambiente hostil, desconfortável aflitivo, as crianças são condicionadas a ser também hostis. Não há leis que possam protegê-las, o que as deixa livres para se tornarem adultos violentos e criminosos. Schaller ${ }^{43}$ reconhece que os dois personagens são representativos da violência existente nesse romance, que se configura um ambiente onde a moral é peculiar, e diz que: "A lei, no mundo de Maggie, basicamente, permite que um código das ruas prevaleça e governe, [...] as raízes da violência estão próximas à superfície no mundo urbano de Maggie. A violência é aceitável na cultura do cortiço”. É o código agressivo das ruas que molda a personalidade beligerante de Jimmie, permitindo sua sobrevivência, mais uma mostra da influência determinista na obra estudada:

As fibras inexperientes dos olhos do garoto endureceram-se bem cedo. Ele tornou-se um rapaz viril. Ele passou alguns anos amargos, sem emprego. Durante esse tempo adquiriu um sorriso crônico de escárnio. Ele estudou a natureza hu- mana na sarjeta, e não a encontrou pior do que imaginava ou acreditava julgá-la. Ele nunca teve respeito pelo mundo, porque ele não possuía ídolos os quais esmagara. ${ }^{44}$

Irving crê que a força dos relacionamentos se dava fora de casa. ${ }^{45} \mathrm{~A}$ descrição minuciosa torna o ambiente palpável, real, sobre o qual Irving aponta que: "O cortiço expõe sua mórbida humanidade, as descrições repulsivas de seus habitantes dissimulando uma ansiedade quase escondida em uma natureza que não se contém de sua alteridade bestial” ${ }^{46}$

O romance explora a luta por espaço nas ruas congestionadas assim como nos cortiços e bares. As pessoas compõem uma grande massa de indivíduos que disputam os espaços relatados por Crane nesse trecho: "A vasta multidão tinha um ar, dos pés à cabeça, de ter acabado de sair do trabalho [...] O grande corpo da multidão era composto por pessoas que mostravam que todos trabalhavam com suas mãos". ${ }^{47} \mathrm{O}$ leitor tem a chance de perceber o ambiente das ruas, abarrotadas de gente se esbarrando umas nas outras no frenesi da cidade grande

Transmudaram-se as calçadas em mares balouçantes de guarda-chuvas. Homens adiantavam-se para chamar bondes ou carruagens, erguendo os dedos em variadas formas de polidas solicitações ou exigências imperativas.

Interminável procissão endereçava-se às estações elevadas. ${ }^{48}$
44. CRANE. Maggie: a Girl of the Streets, p. 15.

45. IRVING. Gendered Space, Racialized Space: Nativism, the Immigrant Woman and Stephen Crane's Maggie, p. 34.

46. IRVING. Gendered Space, Racialized Space: Nativism, the Immigrant Woman and Stephen Crane's Maggie, p. 35.

47. CRANE Maggie: a Girl of the Streets, p. 62.

48. CRANE. Maggie: a Girl of the Streets, p. 62. 
49. MARGOLIS. New York and Literary Imagination: the City in Twentieth Century Fiction and Drama, p. 94.

50. CRANE. Maggie: a Girl of the Streets, p. 37.

51. CRANE. Maggie: a Girl of the Streets, p. 64.
Edward Margolis ${ }^{49}$ observa que os personagens moradores dos cortiços fazem parte integral do ambiente. Aparecem olhos em todos os cantos do conjunto habitacional: "Através das portas abertas, olhos curiosos fitavam Maggie". Os moradores participam dos acontecimentos, espionando a vida dos outros moradores, por trás das portas e janelas dos cortiços, como vemos neste trecho da obra:

Eu estava à porta na noite passada quando sua irmã e o namorado dela chegaram tarde, muito tarde. E ela, coitadinha, chorava como se o seu coraçaozinho fosse partir-se [...] Foi coisa mais engraçada que já vi! E bem aqui na minha porta ela perguntou a ele se ele a amava. ${ }^{50}$

As cercanias do East River são descritas, onde Maggie, enfim, tira a própria vida. A narração de Crane, nos momentos derradeiros de Maggie, sinaliza o fatídico final e recria a atmosfera lúgubre e mórbida propiciada pela descrição do ambiente "[...] escuros distritos perto do rio [...] Ela penetrou a escuridão [...] As venezianas dos altos edifícios estavam fechadas como lábios cruéis". ${ }^{51}$

Penetrou a sombra do derradeiro quarteirão. As venezianas dos altos edifícios estavam cerradas como lábios cruéis. As estruturas pareciam ter olhos que olhavam por cima delas, além delas, para outras coisas. Ao longe, rutilavam as luzes das avenidas como se luzissem de uma distância impossível. As campainhas dos bondes tilintavam com um soar jubiloso. ${ }^{52}$

E termina da seguinte forma:

Ao pé dos altos edifícios surgiu o mortal negrume do rio. Alguma fábrica escondida projetou um clarão amarelo, que iluminou por instantes as águas oleosas, que acavalavam vigamentos de madeira. Os diversos sons da vida, alegrados pela distância e por aparente inacessibilidade, chegaram, timoratos, e morreram no silêncio. ${ }^{53}$

Pensamos que, uma vez que a realidade social do momento está ligada à historicidade de seu tempo, a escrita literária de Crane revela ser uma espécie de testemunho histórico, pois relata e recria o universo de relações sociais existentes naquela época. Portanto, Crane, mesmo partindo de uma percepção pessoal, por meio da familiarização com os problemas na Rua Bowery faz importantes referências sobre as relações sociais, suas influências culturais, tanto internas como externas ao ambiente criado por ele em Maggie. Crane dá uma explicação sociológica ao romance. Ele privilegia a ideia de que o meio ambiente no qual as pessoas vivem exerce influência com força suficiente para que estas não consigam resistir. Maggie enfatiza o fato de que crescer nos cortiços delineia a moral, as crenças e o comportamento das
52. CRANE. Maggie: a Girl of the Streets, p. xiii.

53. CRANE. Maggie: a Girl of the Streets, p. 65.
EM TESE v. 21 
54. SCHALLER. $A$ Vision of American Law: Judging Law, Literature, and the Stories We Tell, p. 104. pessoas. Nova York é desenhada como personagem antagonista, torna-se um obstáculo intransponível para a realização dos desejos da personagem. Por meio de Maggie e de Nova York o autor previne os leitores sobre um ponto de vista de que a virtude oprimida pelo ambiente corrompido e destrutivo pode ser fatal. De acordo com Barry R. Schaller, ${ }^{54}$ o romance reproduz a desilusão do autor em relação ao American Dream, "porque ele tenta mostrar que o ambiente é algo tremendo no mundo e frequentemente molda vidas".

A história da ruína de Maggie é carregada de traços melodramáticos que expõem a fragilidade do ser humano ante as artimanhas da cidade grande, providenciando o tema para uma geração de escritores americanos que repetidas vezes incluíram histórias semelhantes à desenvolvida por Stephen Crane. Constatamos que, em Crane, o drama ficcional da protagonista Maggie espelha uma realidade social conflituosa e cínica, embora o tom de denúncia seja disfarçado pela ironia presente na obra. Por apresentar uma escritura peculiar e inovadora, o autor registra as impressões e faz um retrato crítico da sociedade de sua época. A Maggie das ruas nasce e morre no romance para que seja uma heroína que contraste com as ideias anteriormente desenvolvidas sobre a representação da personagem nos romances naturalistas. Crane previne os leitores, por meio da personagem, sobre um ponto de vista de que a virtude oprimida pelo ambiente corrompido e destrutivo pode ser fatal.

\section{REFERÊNCIAS}

AHNEBRINK, L. The Begginnings of Naturalism in American Fiction: a study of the Works of Hamlin Garland, Stephen

Crane, and Frank Norris Special Reference to Some European Influences. Uppsala, 1950.

ALSBURY, H. As gangs de Nova York: uma história informal do submundo. Tradução de Beatriz Sidou. São Paulo: Globo, 2002.

CRANE, S. Maggie: a Girl of the Street. New York: Batam Dell, 2006.

DOWLING, R. M. Slumming in New York: from the Waterfront to Mythic Harlem. Illinois: University of Illinois Press, 2007.

FELDMAN, E. Prostitution, the Alien Woman and the Progressive Imagination, 1910-1915. American Quaterly, v. 19, n. 2, 1967.

FINE, D. M. Abraham Cahan, Stephen Crane and the Romantic Tenement Tale of Nineties. In: American Studies, v. 14, n. 1, 1993. Disponível em: <https://goo.gl/2yX6ri>. Acesso em: 3 dez. 2010.

GANDAL, K. Stephen Crane's "Maggie" and the Modern Soul. ELH, v. 60, n. 3, p. 759-785, 1993.

HAPKE, L. Girls Who Went Wrong: Prostitutes in American Fiction, 1885-1917. Bowling Green: Bowling Green State University Popular Press, 1989.

HAYES, K. J. Maggie: a Girl of the Streets: a Story of New York. St. Martin's: Bedford, 1999
EM TESE
BELO HORIZONTE
v. 21
N. 3
SET.-DEZ. 2015
CONDE. Nova York selvagem: Imagens da cidade em Maggie [...]
P. $164-178$ 
IRVING, K. Gendered Space, Racialized Space: Nativism, the immigrant Woman and Stephen Crane's 'Maggie'. College Literature, v. 20, n. 3, 1993.

MARGOLIES, E. New York and Literary Imagination: The City in Twentieth Century Fiction and Drama. Jefferson, North Carolina: Mcfarland \& Company, 2008.

PIZER, D.; DOWLING, R. M. A Cold Case File Reopened: Was Crane's Maggie Murdered or a Suicide? In: American Literary Realism. v. 42, n. 1, Illinois: University of Illinois Press, 2009.

SCHALLER, B. R. A Vision of American Law: Judging Law, Literature, and the Stories We Tell. Westpost, CT: Greenwood Publishing Group, 2001

SCHÄTZLE, J. The Reflection of the Metropolis in Stephen

Crane's Maggie: a Girl of the Streets. Munich: GRIN Publishing

$\mathrm{GmbH}, 2000$.

SOLOMON, E. Stephen Crane, From Parody to Realism

Massachussets: Harvard University Press, 1966.

VAHNENBRUCK, K. Fiction of New York: the City as a Metaphor in Selected American Texts. Hamburg: Anchor Academic Publishing, 2013.

WALCUTT, C. C. American Literary Naturalism: a divided stream. Minneapolis: University of Minnesota Press, 1956. 